\title{
Thermal-heating CVD synthesis of BN nanotubes from trimethyl borate and nitrogen gas
}

\author{
Feng-Huei Lin ${ }^{\mathrm{a}, *}$, Chung-King Hsu ${ }^{\mathrm{b}}$, Tzu-Piao Tang ${ }^{\mathrm{b}}$, \\ Pei-Leun Kang ${ }^{c}$, Fan-Fung Yang ${ }^{b}$ \\ ${ }^{a}$ Institute of Biomedical Engineering, College of Medicine and College of Engineering, National Taiwan University Hospital, \\ National Taiwan University, Taipei 106, Taiwan, ROC \\ ${ }^{\mathrm{b}}$ Department of Materials and Mineral Resources Engineering, National Taipei University of Technology, Taipei 106, Taiwan, ROC \\ ${ }^{\mathrm{c}}$ Department of Surgery, Kaoshiung Veterans General Hospital, Taiwan, ROC
}

Received 16 January 2007; received in revised form 21 June 2007; accepted 23 June 2007

\begin{abstract}
Boron nitride $(\mathrm{BN})$ is one of III-V compounds widely applied on the electrical industry. It has been fabricated by numerous techniques, but so far there is no reliable method to produce pure and high-yielding BN nanotubes at relatively lower temperature. Therefore, the exploration on its synthesis is still a challenging subject.

In the study, the BN nanotube would be synthesized by thermal-heating chemical vapor deposition (TH-CVD) with trimethyl borate evaporated at $60^{\circ} \mathrm{C}$ and nitrogen gas flew into reaction chamber as the source of B and N, respectively. 434 stainless steel wires will be coiled as an entangled wire scaffold with pore size of $1 \mathrm{~mm}$ and then placed in the middle part of reaction chamber. The metallic ions contained in the stainless steel will serve as the catalysts for of BN nanotube in situ growth.

From the results of SEM, HRTEM, FTIR and XRD analysis, hexagonal-BN (h-BN) and orthorhombic-BN (o-BN) nanotubes were successfully synthesized at relatively low temperature between 1000 and $1200^{\circ} \mathrm{C}$. All the nanotubes prepared in the system were identified as h-BN and o-BN. At reaction temperature of $1200^{\circ} \mathrm{C}$, several types of $\mathrm{BN}$ morphology appeared. The $\mathrm{BN}$ nanotubes could be obtained at the temperature between 1000 and $1100^{\circ} \mathrm{C}$. However, $\mathrm{BN}$ nanotubes for the latter temperature grow into larger size tube. The optimum reaction temperature for $\mathrm{BN}$ nanotube synthesis is $1000^{\circ} \mathrm{C}$. The reproduction property of synthesized BN nanotube by this method is very promising. The method should have a great potential to prepare BN nanotube in the future.
\end{abstract}

(C) 2007 Elsevier B.V. All rights reserved.

Keywords: Nitride; Nano-structure; Chemical vapour deposition

\section{Introduction}

Boron nitride $(\mathrm{BN})$ is one of the most interesting III-V compounds due to its unique properties, such as low density, high thermal conductivity, excellent mechanical strength wear resistance, stability at high temperatures, and possibility of easy doping with silicon (n-type) and beryllium (p-type). Thus, the material appears as a good alternative for carbon-related materials in several applications [1-3]. BN cannot only form hardy compound but also have excellent optics, electric, thermal conduction and mechanical properties because the negative electricity property is similar to carbons. In addition, carbon

\footnotetext{
* Corresponding author. Tel.: +886 2 23970800x1449; fax: +886223940049 E-mail address: double@ha.mc.ntu.edu.tw (C.-K. Hsu).
}

nanotube demonstrates both conducting and semiconducting property but $\mathrm{BN}$ nanotube behaves as a semiconductor [4] which is more convenient to component development and application in the future.

$\mathrm{BN}$ nanotubes have been fabricated by different techniques, such as arc-discharge, laser ablation, carbon nanotubes templateconfinement and some specifically designed methods [5-9]. Unfortunately, these methods have not been effectively to synthesize a great amount of $\mathrm{BN}$ nanotubes. Very recently, a hazardous procedure of producing high-yield $\mathrm{BN}$ nanotubes via chemical vapor deposition (CVD) of the precursor borazine on nickel boride catalysts has been reported [10]. However, CVD method produced many types of BN structure and contaminated by the nickel boride or catalysts $[11,12]$. So far there is no reliable method to produce pure and high-yield $\mathrm{BN}$ nanotubes therefore, the exploration on its synthesis is still a challenging 
subject. Furthermore, very high reactant temperature is needed to prepare $\mathrm{BN}$ nanotubes from the mentioned methods, such as over $2000^{\circ} \mathrm{C}$ for arc-discharged and over $1200^{\circ} \mathrm{C}$ for traditional CVD method $[13,14]$.

In this study, thermal-heating chemical vapor deposition $(\mathrm{TH}-$ CVD) will be used to synthesize the $\mathrm{BN}$ nanotube by vaporizing trimethyl borate at $60{ }^{\circ} \mathrm{C}$ and providing nitrogen gas to the reaction chamber as the source of $\mathrm{B}$ and $\mathrm{N}$, respectively. 434 stainless steel will be coiled as entangled wire scaffold with pore size of $1 \mathrm{~mm}$. This wire scaffold, thereafter, placed in the middle part of $\mathrm{TH}-\mathrm{CVD}$ reaction chamber. $\mathrm{Cr}, \mathrm{Fe}$, Mo contained in the stainless steel will serve as the catalysts to provide in situ growth of $\mathrm{BN}$ nanotube on the coil surface. We hope the method can produce a great amount of pure $\mathrm{BN}$ nanotube under relatively low temperature. The produced $\mathrm{BN}$ nanotube will be characterized by scanning electron microscope (SEM), high-resolution field-emission transmitted electron microscope (HRTEM), thinfilm X-ray diffractometer (TF-XRD) and Fourier transformation infrared (FTIR).

\section{Materials and methods}

\subsection{Materials preparation}

$\mathrm{BN}$ nanotube is prepared by TH-CVD method with auto-catalyzed process, which is briefly described as follows. 434 stainless steel wire with $0.5 \mathrm{~mm}$ in diameter is coiled in a disk-like shape and placed in the center area of THCVD chamber. The chamber is a pure $\mathrm{Al}_{2} \mathrm{O}_{3}$ tube with $52 \mathrm{~mm}$ in diameter and $60 \mathrm{~cm}$ in length. The tube is sealed on both sides by three-way connector with thermal-resistant O-ring. Ultra pure nitrogen gas and trimethyl borate (TMB) are introduced as the source of $\mathrm{N}$ and $\mathrm{B}$, respectively. TMB was vaporized in a water bath at the temperature of $60^{\circ} \mathrm{C}$ and flow to the TH-CVD chamber via a corrosion-resistant tube. The flow rate of nitrogen gas is $20 \mathrm{~cm}^{3} \mathrm{~min}^{-1}$. A rotary pump is used for ventilation. The ventilation goes through a water tank to remove water-soluble gas for environmental protection. TH-CVD chamber was heated to a temperature in the range of $800-1300{ }^{\circ} \mathrm{C}$ with the heating rate of $3{ }^{\circ} \mathrm{C} \min ^{-1}$ and the maintained for $2 \mathrm{~h}$. The reaction gases will form a stagnant flow to complete the reaction on the surface of 434 stainless steel coil. BN nanotube can be harvested from the coil surface. The design of the TH-CVD device is schemed as Fig. 1 [14].

\subsection{Materials analysis}

The morphology of BN growing on the surface of the stainless steel coil is examined by scanning electron microscope (SEM FE-SEM HITACHI S4100). The specimen is coated with Au-film by sputtering CVD. The film should intensify the back-scattering electron and secondary electron for better resolution. Thin-film X-ray diffraction (TF-XRD) (Rigaku MPA-2000, Japan) is used to

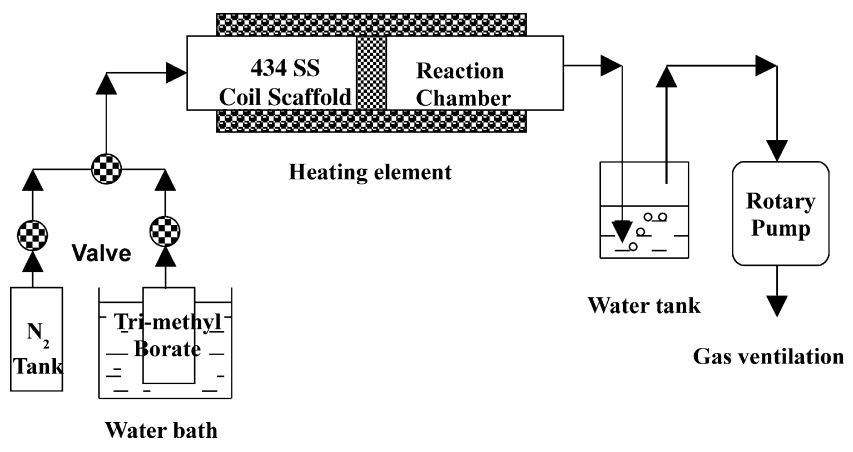

Fig. 1. The scheme of TH-CVD device in the study. analyze the crystal structure of the BN. BN are carefully collected from the coil surface and mounted on the clay cake for scanning. The sample is scanned in a range of $10-90^{\circ}(2 \theta)$ with a scanning rate of $4^{\circ} \mathrm{min}^{-1}$. The functional group and vibration model of the BN nanotube are analyzed by FTIR (JAPAN JASCO FT/IR 410 Series spectrometer). The investigated spectral range was between 400 and $4000 \mathrm{~cm}^{-1}$. A high-resolution transmission field emission electron microscopy (HRTEM Hitachi model HF-2000, $200 \mathrm{keV}$ ) is utilized to analyze the crystal structure and microstructure of BN nanotubes [15]. The stainless steel coil with BN nanotube deposition is placed in an ultrasonic tank for $15 \mathrm{~min}$ in 95\% ethanol. Ethanol with BN nanotube is dripped onto a carbon-coated-copper grid and dried in air for TEM examination. Selected area electron diffraction is performed on HRTEM.

\section{Results}

\subsection{Surface morphology of BN formation at different temperatures}

The BN crystal observed under SEM shows different images in different reaction temperatures. From the morphological examination, they are not all to demonstrate as a tubular structure. At lower temperature, it forms needle-like structure. At higher temperature, it shows a tube-like structure and/or a granular-like structure.

Fig. 2(a) is the image of BN crystal produced at the temperature of $800^{\circ} \mathrm{C}$. BN crystal sporadically appears on the surface of

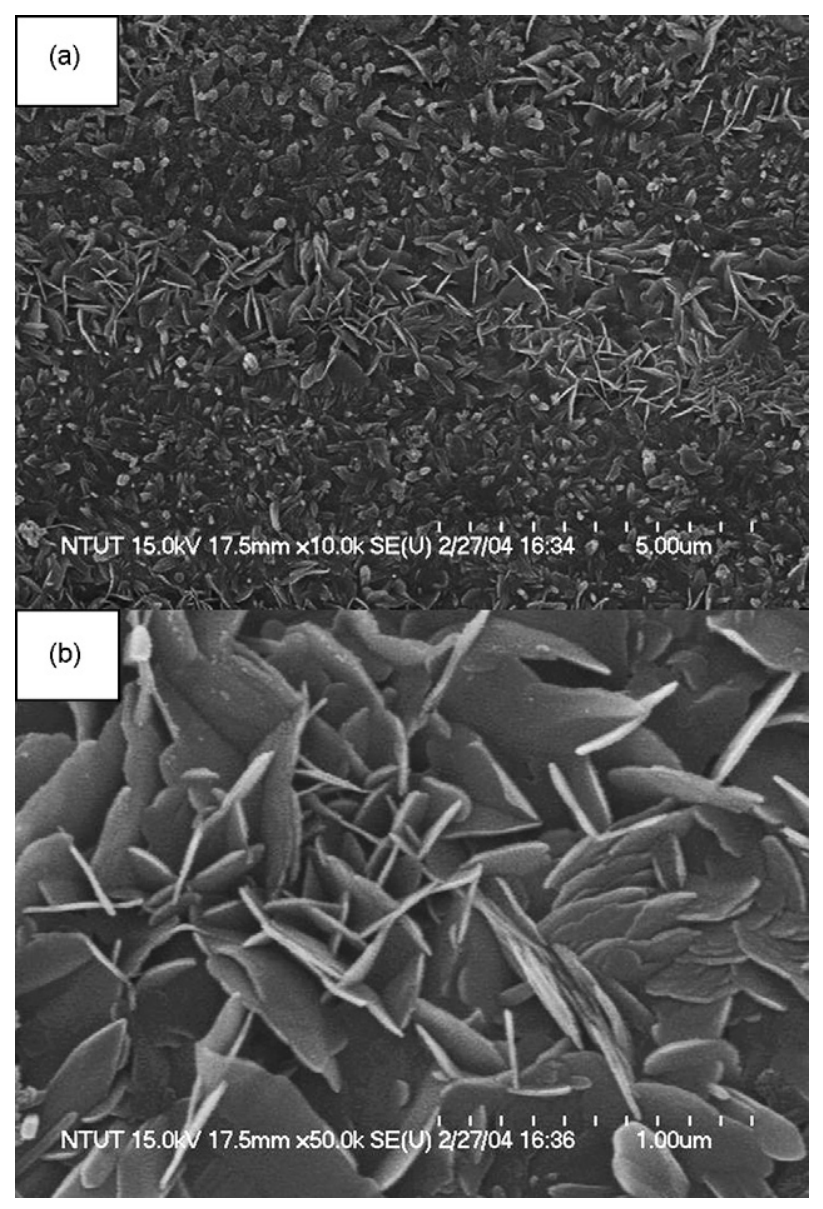

Fig. 2. The image of $\mathrm{BN}$ crystal produced at the temperature of $800^{\circ} \mathrm{C}$ (a) the BN plate structure on the coil surface; (b) take a close examination. 

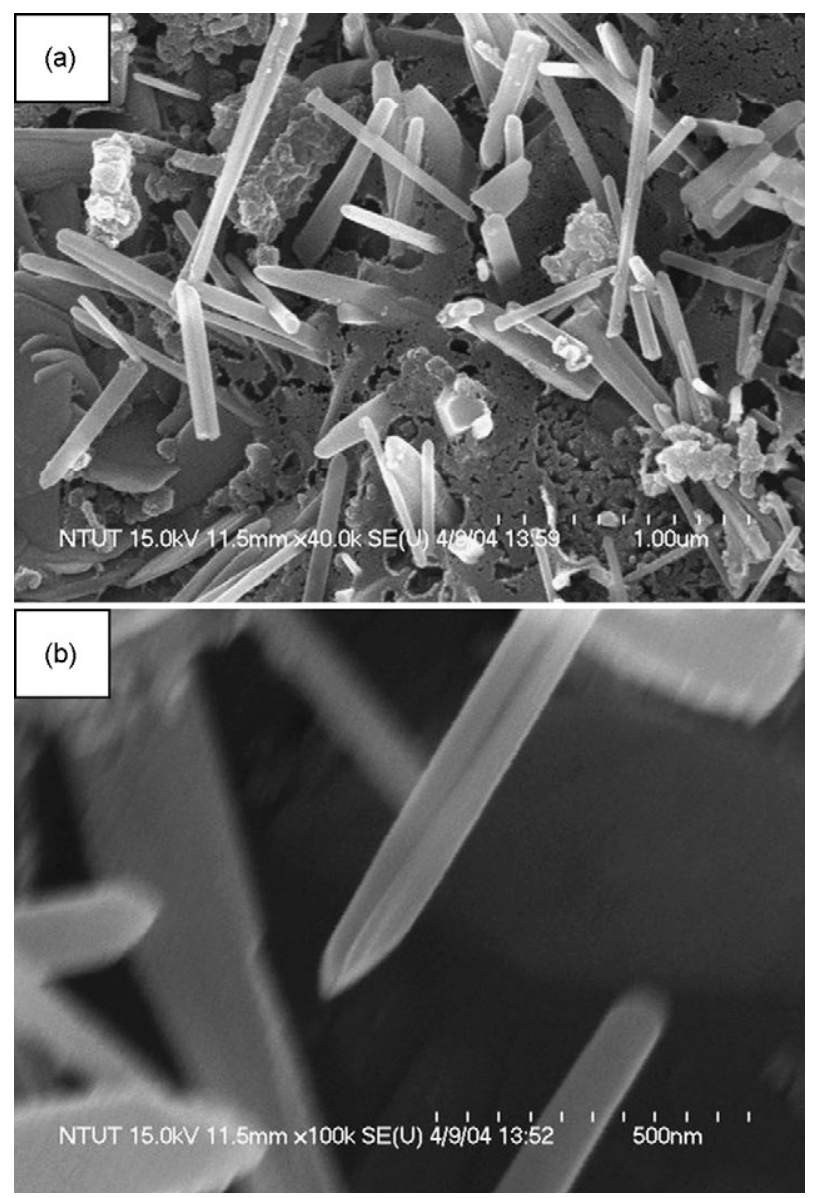

Fig. 3. The image of $\mathrm{BN}$ crystal produced at the temperature of $900^{\circ} \mathrm{C}$ (a) needle-like BN on the coil surface; (b) take a close examination.

the stainless steel coil. The morphology of the $\mathrm{BN}$ is not a tube structure but a plate structure with nano-scale in size as shown in Fig. 2(b). The thickness of the plate is less than $10 \mathrm{~nm}$. No nano-tube or tube-like BN can be observed on coil surface. We believe that the reaction temperature is too lower to crystallize $\mathrm{BN}$ in a larger scale due to low driving force. Higher reaction temperature may solve matter.

When the reaction temperature up to $900{ }^{\circ} \mathrm{C}$ (Fig. 3(a)), the $\mathrm{BN}$ crystal cover the entire area of the stainless steel coil surface. SEM images indicate a needle-like structure, which are $1 \mu \mathrm{m}$ in length and $70 \mathrm{~nm}$ in diameter in average (Fig. 3(b)). The length of BN crystal at $900^{\circ} \mathrm{C}$ is much longer than that of at $800^{\circ} \mathrm{C}$. When the temperature increased, the driving force for crystallization should be increased where the BN needle-like crystals should be a favorable structure.

When the reaction temperature is up to $1000^{\circ} \mathrm{C}, \mathrm{BN}$ is crystallized like a tubular structure with $70 \mathrm{~nm}$ in diameter and $4 \mu \mathrm{m}$ in average length (Fig. 4(a)). The microstructure of BN crystal at a reaction temperature of $1100^{\circ} \mathrm{C}$ is similar to that of $1000^{\circ} \mathrm{C}$ (Fig. 4(b)).

When the reaction temperature is up to $1200^{\circ} \mathrm{C}$, there are many types of BN appeared on the stainless steel coil surface such as wire, bead string structure, and bamboo like tube as shown in Fig. 5.
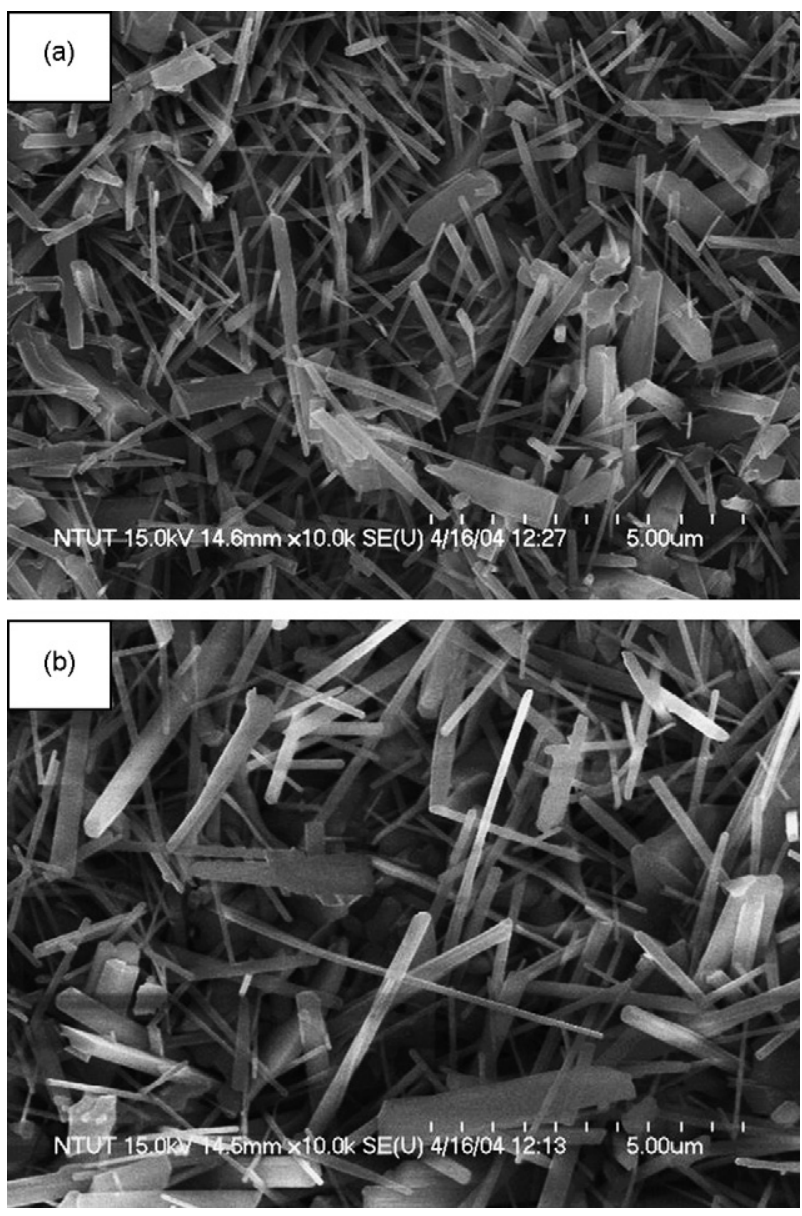

Fig. 4. The image of $\mathrm{BN}$ nanotube produced at the temperature of (a) $1000^{\circ} \mathrm{C}$; (b) $1100^{\circ} \mathrm{C}$.

Fig. 6(a) is the morphology of $\mathrm{BN}$ at $1300^{\circ} \mathrm{C}$. BN crystals seems like a granular structure but most of them are hollow inside. As shown in Fig. 6(b), the tube grows out and expands to the surrounding to form a facet crystal.

From the SEM observations, the BN nano-tube in the study can be formed at the temperature in the range of $1000-1200^{\circ} \mathrm{C}$. We will narrow the reaction temperature range in the later experiment.

\subsection{XRD characteristics of $B N$ nanotubes}

The XRD patterns of $\mathrm{BN}$ deposited at 1200 and $1000^{\circ} \mathrm{C}$ are shown in Fig. 7(a) and (b), respectively. Fig. 7(c) and (d) is the patterns for clay and 434 stainless steel, respectively. If the peaks corresponding to clay and 434 stainless steel subtracted, the XRD patterns of $\mathrm{BN}$ deposited at 1200 and $1000^{\circ} \mathrm{C}$ are identified as orthorhombic boron nitride (o-BN) and hexagonal boron nitride (h-BN), respectively.

\subsection{Characteristics of BN crystal}

FTIR was used to analyze the functional groups of the BN deposited on stainless steel coil. Fig. 8 shows the FTIR pattern of $\mathrm{BN}$ nanotubes produced at the temperature of $1000^{\circ} \mathrm{C}$. The 

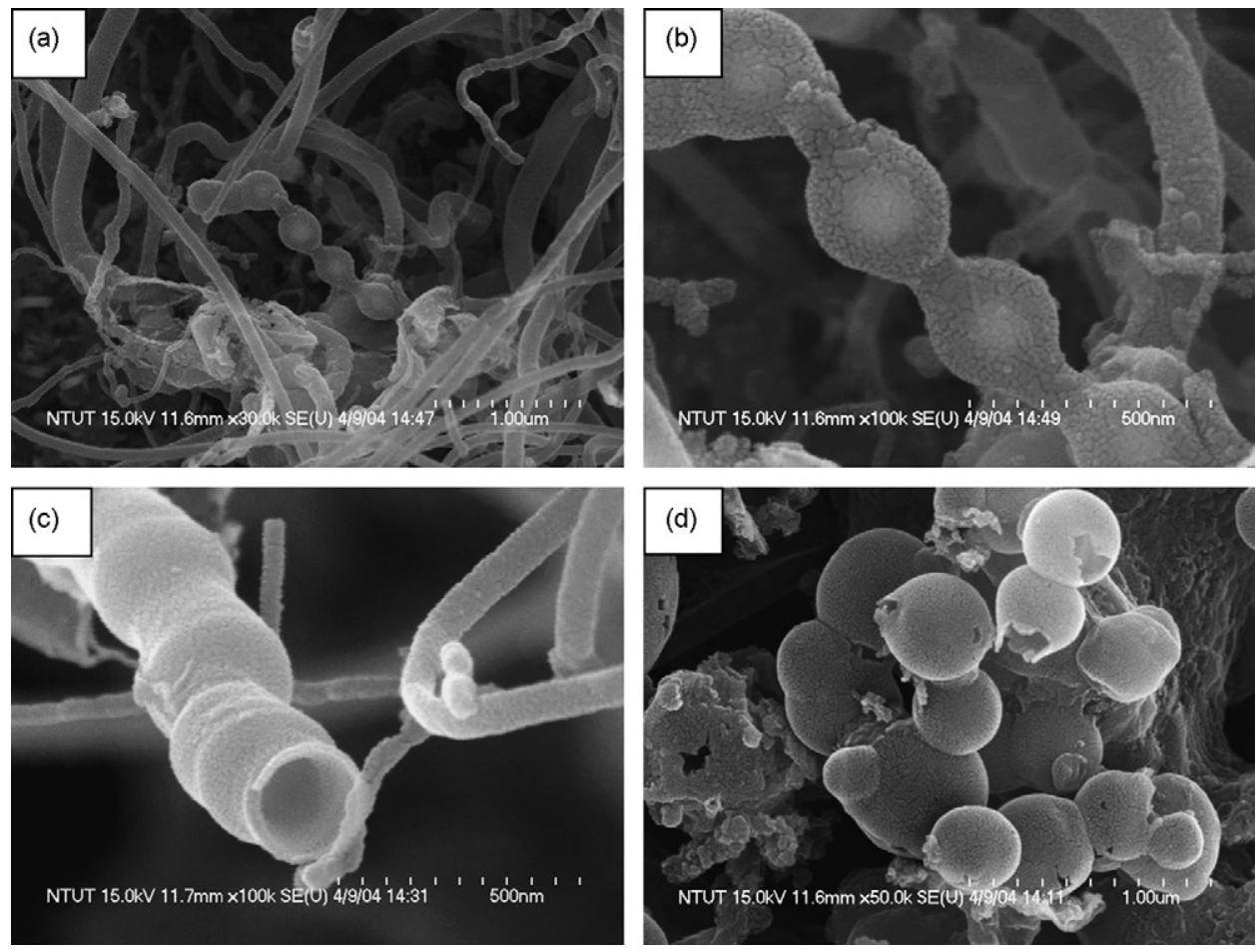

Fig. 5. The image of $\mathrm{BN}$ nanotubes produced at the temperature of $1200^{\circ} \mathrm{C}$ (a) many types of $\mathrm{BN}$ morphology; (b) bead string structure; (c) bamboo like tube; (d) bead like structure.
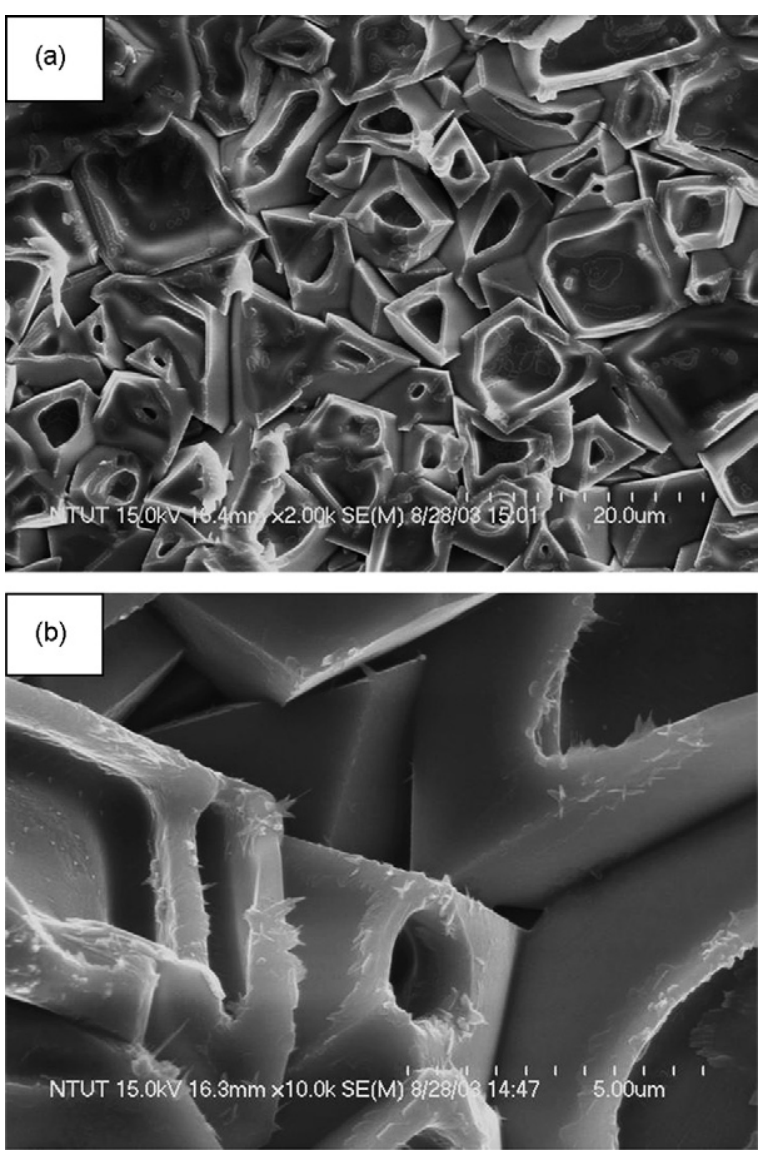

Fig. 6. The morphology of $\mathrm{BN}$ crystal at the temperature of $1300^{\circ} \mathrm{C}$ (a) $\mathrm{BN}$ crystal on coil surface; (b) the tube grows out to form a facet crystal. absorption bands at the wavenumber of 1360 and $785 \mathrm{~cm}^{-1}$ are attributed to the $\mathrm{B}-\mathrm{N}$ stretching and $\mathrm{B}-\mathrm{N}-\mathrm{B}$ bending of $\mathrm{BN}$, respectively. The FTIR patterns at 1100 and 1200 are similar to that of $1000^{\circ} \mathrm{C}$. This result further proves that the deposited crystal in this study is BN nanotubes.

\subsection{Transmission and electric diffraction patterns of $B N$ nanotubes}

Fig. 9(a) shows the TEM image of BN nanotube produced at $1000^{\circ} \mathrm{C}$. The diameter of nanotube is about $50 \mathrm{~nm}$.

(a)

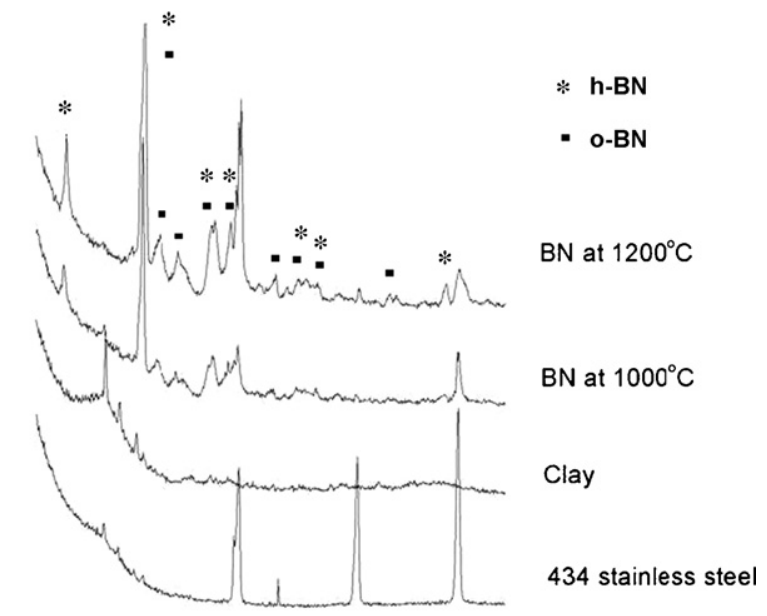

\begin{tabular}{cccccc}
\hline 1 & 1 & 1 & 1 \\
20 & 40 & 60 & 80 & 100 \\
& $2-T h e t a($ degree) & &
\end{tabular}

Fig. 7. The XRD patterns of $\mathrm{BN}$ nanotube deposited at the reaction temperature of (a) $1200^{\circ} \mathrm{C}$; (b) $1000^{\circ} \mathrm{C}$; (c) clay; (d) 434 stainless steel. 


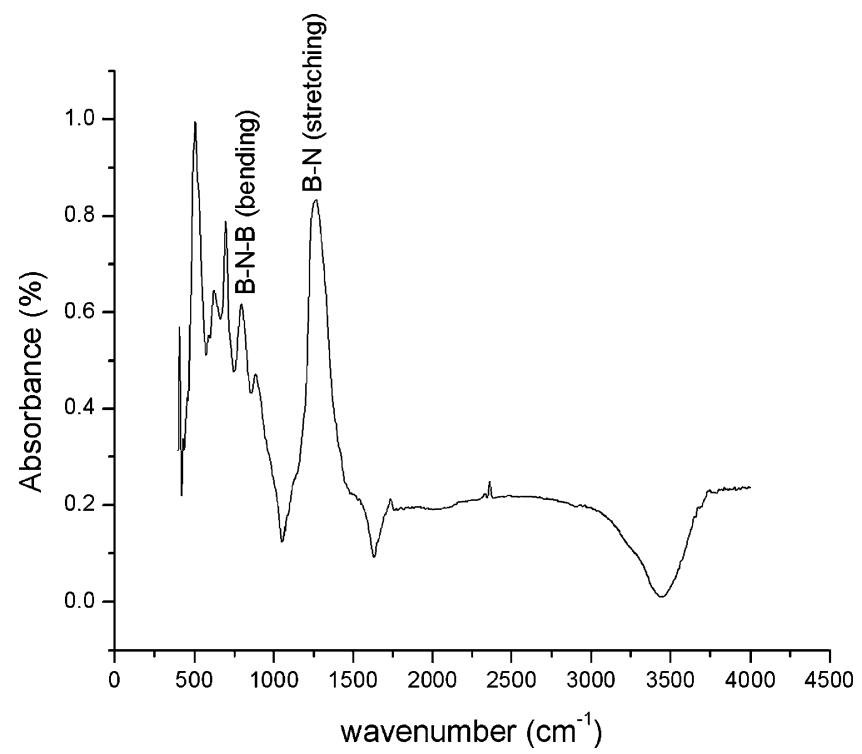

Fig. 8. The FTIR pattern of $\mathrm{BN}$ nanotubes produced at the temperature of $1000^{\circ} \mathrm{C}$.

Fig. 9(b) is the diffraction pattern of the TEM image which shows a ring pattern with four clear rings on the pattern. The four rings from inner part to the outer are identified

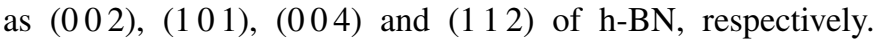

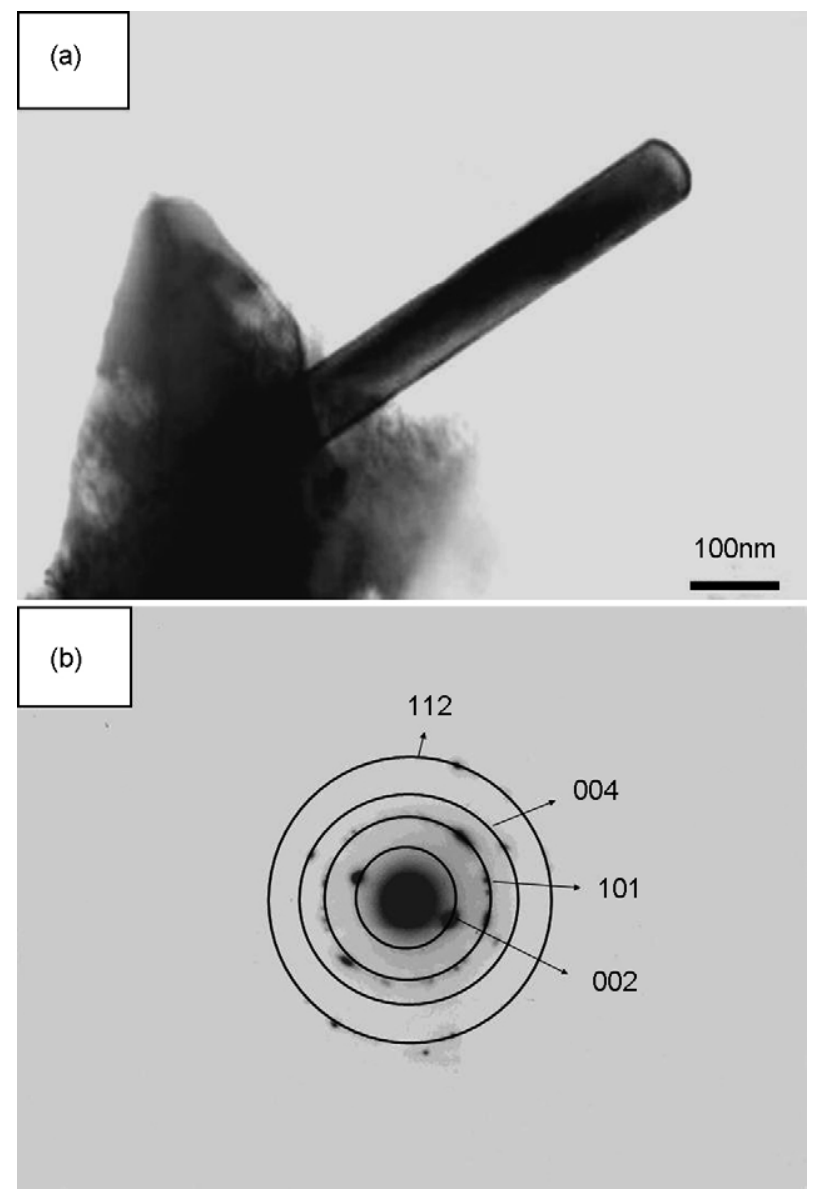

Fig. 9. (a) The TEM image of BN nanotube produced at the temperature of $1000^{\circ} \mathrm{C}$; (b) the diffraction pattern of the image.
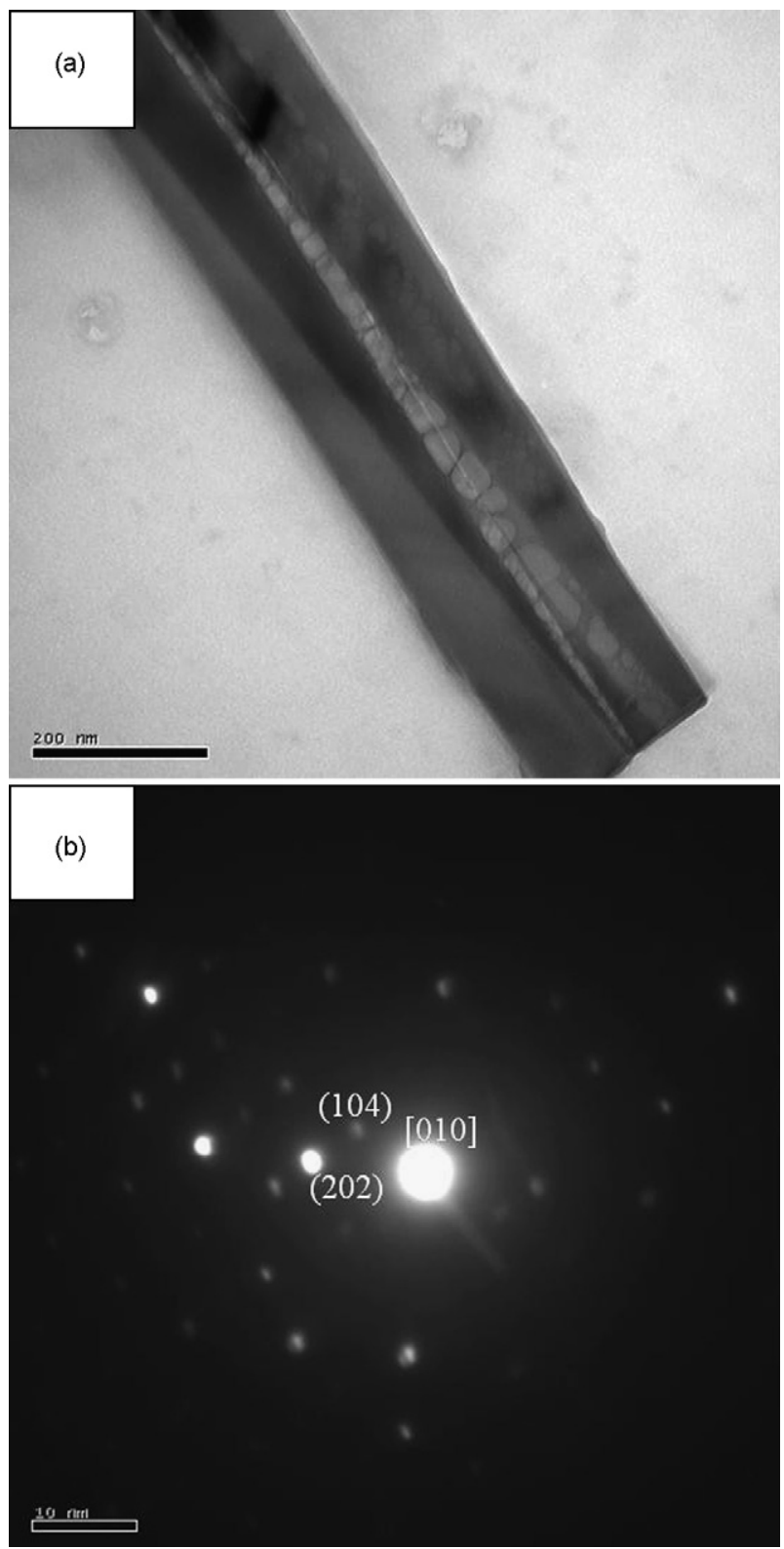

Fig. 10. (a) A multi-walled $\mathrm{BN}$ nanotube produced at the temperature of $1000^{\circ} \mathrm{C}$; (b) the diffraction pattern of the image.

Fig. 10 (a) shows a multi-walled $\mathrm{BN}$ nanotube produced at $1000{ }^{\circ} \mathrm{C}$ that outer diameter is $150 \mathrm{~nm}$ and inner diameter is about $35 \mathrm{~nm}$. We can observe a spiral growth in the nanotube structure. The diffraction pattern is identified as h-BN (Fig. 10(b)).

Fig. 11(a) is the TEM image of BN nanotube produced at $1200^{\circ} \mathrm{C}$. Fig. 11 (b) is the lattice image of Fig. 11(a). The lattice distance of the pattern is about $3.345 \AA$ that is corresponding to $\left(\begin{array}{lll}0 & 0 & 2\end{array}\right)$ plane of $\mathrm{h}-\mathrm{BN}$. As observed in SEM, BN also demonstrate several types of morphology as shown in Fig. 12(a). Most of the tip of the BN nanotubes produced at $1200^{\circ} \mathrm{C}$ is closed with the axial sequence of inverted conical void (Fig. 12(b)). Although different types of morphology shown, BN nanotubes produced at $1200{ }^{\circ} \mathrm{C}$ are h-BN. 

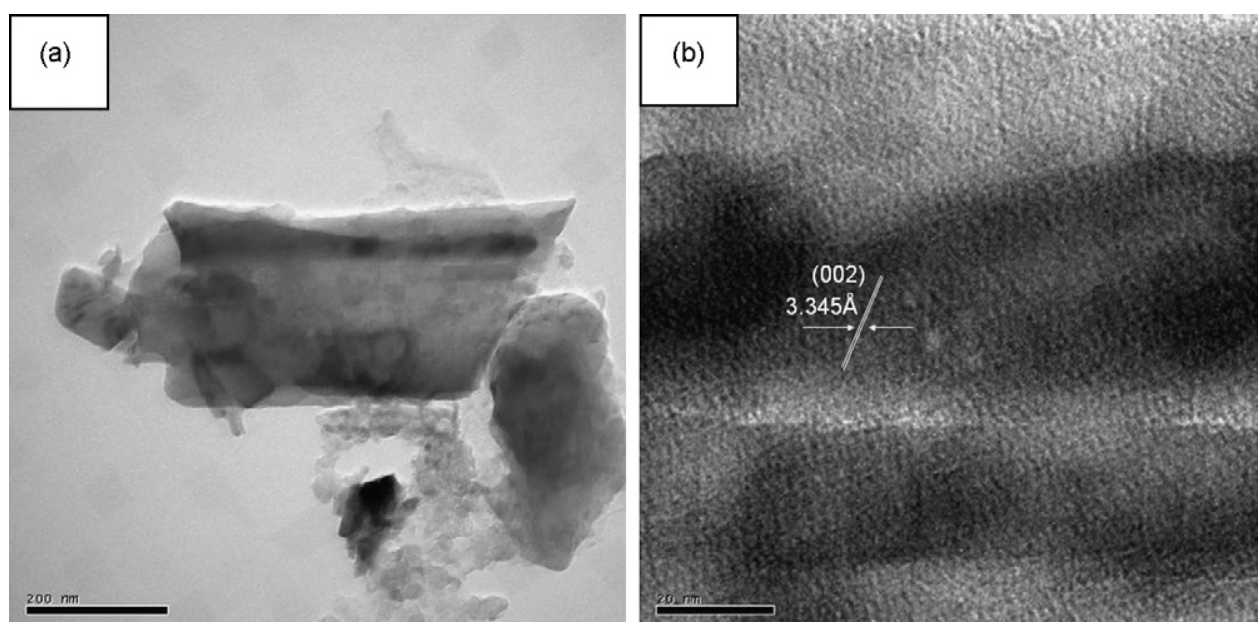

Fig. 11. (a) The TEM image of $\mathrm{BN}$ nanotube produced at the temperature of $1200^{\circ} \mathrm{C}$; (b) the lattice image of the nanotube.

\section{Discussions}

Crystal growth of one-dimensional structure requires a pathway to continuously providing gas- or liquid-phase reactants to a specified site, in which an anisotropic driving force exists to assure an oriented growth $[15,16]$. When gas reactants and liquid impurity (catalyst) are used, the vapor-liquid-solid (VLS) growth mechanism is responsible for the synthesis of wirelike structure [17]. Morales and Lieber synthesized $\mathrm{Si}$ and $\mathrm{Ge}$ nanowires by combining laser ablation and a V-L-S method [18]. This technique can produce nano-scale liquid catalysts, which determine the diameter of nanowires.

In the study, the overall reaction to produce BN crystal is as follows:

$$
\mathrm{C}_{3} \mathrm{H}_{9} \mathrm{BO}_{3(\mathrm{~g})}+\mathrm{N}_{2(\mathrm{~g})} \rightarrow \mathrm{BN}_{(\mathrm{s})}+\mathrm{NH}_{3(\mathrm{~g})}+3 \mathrm{CO}_{(\mathrm{g})}
$$

The residual gases of $\mathrm{NH}_{3(\mathrm{~g})}+3 \mathrm{CO}_{(\mathrm{g})}$ are removed from the reaction system through a water tank by a rotary pump. BN crystals formed on the coil surface and catalyzed by the $\mathrm{Fe}, \mathrm{Cr}$, Mo elements provided from the surface of the coil scaffold.

At lower temperature, catalysts are difficult to combine with absorbed reactant gases and reach a liquid eutectic composition. In this condition, the BN crystal deposited on the 434 stainless steel coil surface is epitaxial growth. The crystal orientation should be matched to the crystal orientation of coil substrate. A plate-like morphology is the most favorable as shown in Fig. 2. When the temperature increased to the $900^{\circ} \mathrm{C}$, the crystal growth is also based on epitaxial growth but the growth rate is much faster than that of at $800^{\circ} \mathrm{C}$ due to higher driving force. This leads to a needle-like structure not a hollow tube, as shown in Fig. 3.

When the temperature is up to $1000^{\circ} \mathrm{C}, \mathrm{Fe}, \mathrm{Cr}$, or Mo will combine with the reactant gases to reach a eutectic composition to form a partial liquid on the surface. The $\mathrm{V}-\mathrm{L}-\mathrm{S}$ mechanism to form the $\mathrm{BN}$ nanotube occurs at $1000^{\circ} \mathrm{C}$ as shown in Fig. 4. If the temperature increased to $1100^{\circ} \mathrm{C}, \mathrm{BN}$ nanotube also appeared on the coil surface as the same mechanism as $1000^{\circ} \mathrm{C}$. Nevertheless, the nanotubes decreased in size are due to coalescence phenomena to eliminate excessive surface energy.

When temperature increases to $1200^{\circ} \mathrm{C}, \mathrm{Fe} \mathrm{Cr}$, or Mo partial pressure in the reaction chamber will increase. $\mathrm{BN}$ crystals growth mechanism at this temperature is not only $\mathrm{V}-\mathrm{L}-\mathrm{S}$ but also $\mathrm{V}-\mathrm{S}$ or $\mathrm{L}-\mathrm{S}$ that causes many kinds of $\mathrm{BN}$ morphology to present on the coil surface (Fig. 5). In addition, the growth process of the nanotube in the study is the axial sequence of inverted conical void (Fig. 12). The mechanism has been proposed for BN nanotube growth by catalytic capillary [19-22]. When temperature is up to $1300^{\circ} \mathrm{C}$, there are no nanotubes or wires to form
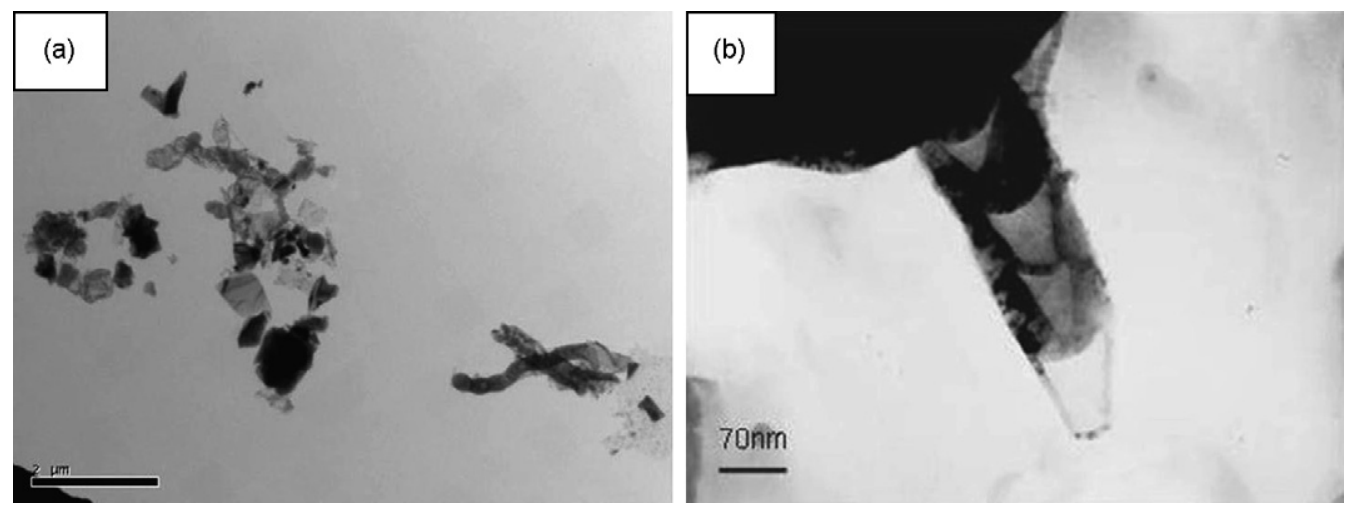

Fig. 12. (a) Several types of morphology at the temperature of $1200^{\circ} \mathrm{C}$; (b) the $\mathrm{BN}$ nanotube is tip closed with the axial sequence of inverted conical void. 
on the coil surface. It becomes granular structures with hollow inside due to tube fast growth to minimize the surface energy.

From the study of XRD analysis (Fig. 7), the BN deposited on the substrate is identified as two types of $\mathrm{BN}$ crystal structure (h-BN and o-BN). However, all the nanotubes are identified as hBN by FTIR, TEM, and HR-TEM. The h-BN nanotubes can be obtained between the temperatures of 1000 and $1100^{\circ} \mathrm{C}$, which is relatively low for the $\mathrm{BN}$ nanotubes preparation.

\section{Conclusions}

In this study, BN nanotubes were successfully synthesized at relatively low temperature between 1000 and $1100^{\circ} \mathrm{C}$. All the nanotubes prepared in the system were identified as h-BN that was formed on the o-BN template. When the reaction temperature is $1200^{\circ} \mathrm{C}$, there are many types of h-BN morphology appeared. BN nanotubes formed at $1100{ }^{\circ} \mathrm{C}$ are larger than the one at $1000^{\circ} \mathrm{C}$. The optimum temperature for BN nanotube synthesis is $1000^{\circ} \mathrm{C}$. The reproduction property of synthesized $\mathrm{BN}$ nanotube by this method is very stable comparing with conventional methods. This method should have a great potential to prepare $\mathrm{BN}$ nanotube in the future.

\section{References}

[1] D. Golberg, Y. Bando, M. Mitome, Physica B 323 (2002) 60.
[2] R. Zedlitz, M. Heintze, M.B. Schubert, J. Non-Cryst. Solids 198 (1996) 403.

[3] A. Zettl, Adv. Mater. 5 (1996) 443.

[4] E. Bengu, L.D. Marks, Phys. Rev. Lett. 86 (2001) 2385.

[5] N.G. Chopra, R.J. Luyken, K. Cherrey, C.H. Crespi, M.L. Cohen, S.G. Louie, A. Zettl, Science 269 (1995) 966.

[6] J. Cumings, A. Zettl, Chem. Phys. Lett. 316 (2000) 211.

[7] A. Loiseau, F. Willaime, N. Demoncy, G. Hug, H. Pascard, Phys. Rev. Lett. 76 (1996) 4737.

[8] R. Tenne, L. Margulis, M. Genut, G. Hodes, Nature 360 (1992) 444.

[9] W. Han, Y. Bando, K. Kurashima, T. Sato, Appl. Phys. Lett. 73 (1998) 3085.

[10] O.R. Lourie, C.R. Jones, B.M. Bartlett, P.C. Gibbons, R.S. Ruoff, W.E. Buhro, Chem. Mater. 12 (2000) 1808

[11] C.C. Tang, X.X. Ding, X.T. Huang, Z.W. Gan, Chem. Phys. Lett. 356 (2002) 254.

[12] R. Ma, Y. Bando, Sci. Technol. Adv. Mater. 4 (2003) 403.

[13] D. Golberg, Y. Bando, K. Kurashima, T. Sato, Solid State Commun. 116 (2000) 1.

[14] F.H. Lin, C.K. Hsu, G.Y. Lin, Z.B. Tang, Mater. Chem. Phys. 9 (2005) 10.

[15] F.H. Lin, C.H. Chen, Winston T.K. Cheng, Biomaterials 27 (2006) 3333.

[16] A.W. Vere, Crystal Growth, Principles and Progress, Plenum Press, New York, 1987 (Chapter 1).

[17] T.J. Trentler, K.M. Hickman, S.C. Goel, A.M. Viano, P.C. Gibbons, W.E. Buhro, Science 270 (1995) 1390.

[18] R.S. Wagner, W.C. Ellis, Appl. Phys. Lett. 4 (1964) 99

[19] A.M. Morales, C.M. Lieber, Science 279 (1998) 1384.

[20] Y. Satio, Carbon 33 (1995) 979.

[21] V.V. Kovalevski, A.N. Safronv, Carbon 36 (1998) 963.

[22] T.L. Chadderton, Y. Chen, J. Cryst. Growth 240 (2002) 164. 